\title{
Assessment of Mycotoxins in Edible Tree Borne Oil Seeds (TBOS)
}

\author{
Punam K. Singh ${ }^{1}$ \\ ${ }^{1}$ Regional Director, IGNOU Regional Centre, Saharsa, India \\ Correspondence: Punam K. Singh, Regional Director (IGNOU), House No. 76/7 Nashvilla Road, Dehradun \\ (Uttarakhand) 248001, India. Tel: 91-135-265-5754 (R), 91-947-319-4353. E-mail: punamksingh@yahoo.co.in; \\ punamksingh@ignou.ac.in
}

$\begin{array}{lc}\text { Received: January 6, } 2012 & \text { Accepted: January 19, } 2012 \text { Online Published: May 29, } 2012 \\ \text { doi:10.5539/jfr.v1n3p92 } & \text { URL: http://dx.doi.org/10.5539/jfr.v1n3p92 }\end{array}$

\begin{abstract}
Assessment of mycoflora and mycotoxins associated with Tree Borne Oil Seeds (TBOS) namely Buchanania lanzan Spreng. (chironji), Juglans regia Linn. (walnut), Prunus armeniaca Linn. (apricot) and Shorea robusta Gaertn. (sal) indicates Aspergillus flavus, A. niger and Penicillium citrinum as the most frequently occurring fungi. Significant variation in pattern of mycoflora incidence was observed in fresh \& stored samples. Mycotoxin producing fungi were screened under laboratory conditions for their ability to produce mycotoxins. The percentage toxigenicity was higher in the isolates of $A$. flavus in comparison to other mycotoxigenic fungi. In B. lanzan, twenty six percent isolates of $A$. flavus were toxigenic and produced up to $26 \mu \mathrm{g} / \mathrm{ml}$ aflatoxin $\mathrm{B}_{1}$ in the liquid media followed by $J$. regia $(19 \mu \mathrm{g} / \mathrm{ml})$, P.armeniaca $(4 \mu \mathrm{g} / \mathrm{ml})$ and $S$. robusta $3.5 \mu \mathrm{g} / \mathrm{ml})$. Stored samples exhibited high concentration of aflatoxin B1 when analysed for natural occurrence of mycotoxins. Level of aflatoxin $\mathrm{B}_{1}$ recorded in P. armeniaca, S. robusta, J. regia and B. lanzan was up to $0.98 \mu \mathrm{g} / \mathrm{g}, 0.91 \mu \mathrm{g} / \mathrm{g}, 0.54$ $\mu \mathrm{g} / \mathrm{g}$ and $0.48 \mu \mathrm{g} / \mathrm{g}$ respectively. The level of other mycotoxins citrinin, ochratoxin and zearalenone were comparatively low. Analysis of oil extracted from fungal infected stored samples showed presence of aflatoxins in natural occurrence. Incidence of aflatoxin $B_{1}$ was higher in apricot oil (up to $0.32 \mu \mathrm{g} / \mathrm{g}$ ), up to $0.28 \mu \mathrm{g} / \mathrm{g}$ in chironji and walnut oil whereas in sal butter up to $0.23 \mu \mathrm{g} / \mathrm{g}$. TBOS under study exhibited significant reduction in the oil content during fungal infection, however, reduction was more prominent in case of A. flavus in all cases.
\end{abstract}

Keywords: tree borne oil seeds (TBOS), mycotoxins, aflatoxin

\section{Introduction}

Tree borne oilseeds (TBOS) also known as minor oilseeds is a potential non-conventional source of edible oils. India has been bestowed with vast forest areas, which contain a rich flora, oilseeds being a part of it. Several forest species yield oil seeds, which are commercially important and are available in large quantities. Many of the oilseeds are edible and generally used for food in various forms, such as butter substitute, salad dressings, confectionery etc.

The fungi being ubiquitous in nature invade seeds during harvesting, collection and storage. Practices used in harvesting, handling, storage, production and distribution make the produce subject to contamination by various fungi including mycotoxin producing fungi (Shukla \& Singh, 2006). These fungi are responsible for spoilage and production of mycotoxins in the substrate. The concern over quality of these products is mainly due to their potential contamination by storage fungi namely, Aspergillus flavus, A. parasiticus and Penicillium citrinum producing aflatoxins and citrinin respectively. Mycotoxins are worldwide important problem in terms of public health, agriculture and economics. In spite of extensive research on the occurrence of mycotoxins in foods, only few reports available on the incidence of toxigenic mycoflora and mycotoxins in TBOS (Singh \& Shukla, 2008). These fungi readily colonize several important crops, TBOS being one of them. Aflatoxins can be produced in preharvest as well as in stored products (Wilson \& Payne, 1994).

Aspergillus flavus group of fungi produce secondary metabolites called aflatoxins, which are highly toxic, mutagens and carcinogens in animal and human beings (Hesseltine, 1965; Ainsworth \& Austwick, 1973). They may also be involved to some degree of liver cancer in human (Rensburg et al., 1965). Aflatoxins have been implicated in hepatocellular carcinoma, acute hepatitis, Reye's syndrome, cirrhosis in malnourished children and Kwashiorkar (Gourama \& Bullerman, 1995; Jelinel et al., 1989). 
The content and quality of oil extracted from oilseeds are greatly affected by storage conditions and mould growth. High moisture content and injured seed coats influence the oil content and quality of oilseeds. Changes like increased acidity and decreased lipid, carbohydrate and proteins are reported to occur. Invasion of seeds by storage fungi may result in increase in free fatty acid, decrease in non-reducing sugar, development of musty odours and discoloration. A preliminary study on some edible oilseeds infected with toxigenic strain of Aspergillus flavus indicate reduction of some fatty acids.

The present study was conducted to evaluate the predominant flora, extent of fungal contamination and assessment of mycotoxin contamination in oilseeds and oil extracted from the samples and estimation of changes in the total oil content during fungal infection. Based on the economic and commercial potential, seed kernels of Buchanania lanzan Spreng. (chironji), Juglans regia Linn. (walnut), Prunus armeniaca Linn. (apricot) and Shorea robusta Gaertn. (sal) were selected. Of these, B. lanzan and $J$ regia kernels are valued as dessert, oil extracted possess medicinal properties and are extensively used in confectioneries. $P$. armeniaca is used as a table fruit and the oil extracted from dry kernels is used for cooking as well as in pharmaceutical and cosmetic industries. S. Robusta seed kernels yield sal butter, eaten raw or roasted and generally used as cooking oil. Sal seed oil is used as butter substitute and also substitute for cocoa in the manufacture of chocolates.

\section{Material and Methods}

\subsection{Collection of Samples}

Fresh samples of fruits/ seeds were collected from different forest division of Himalayan region of Uttarakhand. Stored fruits/ seeds were collected from different storage centres located in Garhwal and Kumaun regions of Uttarakhand state of India.

\subsection{Mycoflora Counts}

To record the fungal flora associated with fresh and stored fruit/ seed samples, blotter test as well as agar plate methods as recommended by International Seed Testing Association (ISTA, 1999) were followed. Isolation of mycoflora was done from the surface sterilized samples to isolate the internal fungi and unsterilized samples to isolate the surface fungi. For surface sterilization the samples were soaked in $2 \%$ sodium hypoclorite (NaOCI) solution for 10 minutes. Subsequently the seeds, fruits were thoroughly rinsed in sterile distilled water and aseptically placed in Petri plates containing three layered moistened blotter pads and Potato Dextrose Agar medium. The Petri plates were then incubated for seven days at $25 \pm 2^{\circ} \mathrm{C}$. The Petri plates were regularly examined under sterioscopic binocular microscope from third day and developing fungal colonies were recorded, isolated, identified and maintained on PDA and Czapek's-dox agar media.

\subsection{Assessment of MyCotoxins}

\subsubsection{Toxigenic Potential of Mycotoxin Producing Fungi}

The aflatoxin producing potentials of Aspergillus flavus Link ex Fries isolates were tested in SMKY liquid medium (Diener \& Davis, 1966). The constituents of the medium were, Yeast extract - 7g; Sucrose - 200g; Magnesium Sulphate $\left(\mathrm{MgSO}_{4} 7 \mathrm{H}_{2} \mathrm{O}\right)-0.5 \mathrm{~g}$; Potassium Nitrate $\left(\mathrm{KNO}_{3}-3 \mathrm{~g}\right.$; Distilled water $-1 \mathrm{lt}$. All isolates of Aspergillus ochraceus and Penicillium citrinum were screened for their ochratoxin and citrinin level respectively by inoculating them in the liquid media composed of Sucrose - $40 \mathrm{~g}$; Yeast extract - $20 \mathrm{~g}$; Distilled water - $1 \mathrm{lt}$ (Schwenk et al., 1958; Davis et al., 1972). Zearalenone producing ability of isolates of Fusarium was evaluated on moist - rice medium (Scott et al., 1970).

All flasks were incubated at $28 \pm 2^{\circ} \mathrm{C}$ foe 11 days and then filtered. The filtrate was extracted with chloroform and the conc. chloroform extract stored in vials were for qualitative and quantitative detection of mycotoxins as detailed in section 2.3.3 and 2.3.4.

\subsubsection{Natural Occurrence of Mycotoxins}

The fresh and stored kernels of oilseeds were extracted chemically for the presence of aflatoxins by the method of Thomas et al. (1975). Few samples, in which fungi producing other mycotoxins were associated, were extracted by the method of Roberts and Patterson (1975). The chloroform extract were used for qualitative and quantitative detection of mycotoxins as detailed in section 2.3.3 and 2.3.4.

\subsubsection{Qualitative Detection and Chemical Confirmation of Mycotoxins}

Qualitative and quantitative estimation of the mycotoxins were carried out using Thin Layer Chromatography (TLC). Silica Gel - G (with $13 \% \mathrm{CaSO}_{4}$ as binder) was used as stationery phase for the TLC. $50 \mu 1$ of chloroform 
extract was spotted on TLC plates along with the standards obtained from Sigma, USA. The spotted chromoplate was developed in the solvent system comprising Toluene: isoamyl alcohol: methanol (90: 32:2, v/v/v). After developing, the plates were air dried and were observed under long (360nm) and short (260) wavelengths UVlight for the detection of mycotoxins.

Chemical confirmation of aflatoxin was done by Trifluoroacetic acid (TFA) as suggested by Stack and Pohland (1975). Presence of Ochratoxin on TLC plates was confirmed with ammonia fumes which changed blue green spot to deep blue colour (Davis et al., 1969). Confirmation of citrinin was done by spraying TLC plates with freshly prepared mixture of $0.5 \mathrm{ml} \mathrm{p}$ - anisaldehyde in $85 \mathrm{ml}$ of methanol containing $10 \mathrm{ml}$ of glacial acetic acid and $5 \mathrm{ml}$ of conc. $\mathrm{H}_{2} \mathrm{So}_{4}$ and then by heating the plate at $130^{\circ} \mathrm{C}$ for 10 minutes. This changed yellow streak of citrinin to yellowish green under long wave UV- light (Scott et al., 1970). Zearalenone was also confirmed by spraying TLC plates with acidic p- anisaldehyde solution (Scott et al., 1970) by which greenish blue fluorescence turned faint brown (in visible light) and faint yellow in long wave UV- light.

\subsubsection{Quantitative Estimations of Aflatoxin}

Aflatoxin being most potent mycotoxin, the quantitative estimation for the same was carried out. Quantity of aflatoxin was estimated spectrophotometrically (Nabney \& Nesbitt, 1965) with the help of UVSpectrophotometer.

\subsubsection{Estimation of Oil Content}

To estimate changes in oil content during fungal infection, the oilseeds were inoculated with test fungi selected on the basis of its percentage incidence (Shukla et al., 2009). The oilseed kernels were surface sterilized with $2 \%$ sodium hypochlorite solution, washed thoroughly with sterile distilled water, inoculated with spore suspensions (250-350spores $/ \mathrm{ml}$ ) of A. flavus Link ex Fries, A. niger Van Teigh and Penicillium citrinum Thom, and incubated for 11 days at $96 \%$ relative humidity. Changes in oil content in healthy and fungal infected samples were determined by extraction in a soxhlet apparatus (AOAC, 1984). For extraction of oil, the dried and crushed seed kernels were extracted with petroleum ether $\left(60-80^{\circ} \mathrm{C}\right)$ for $8 \mathrm{hrs}$. in a soxhlet apparatus. The extract was dried over anhydrous sodium sulphate for half an hour. It was then filtered and freed from the solvent on a water bath. Physico-chemical properties of the oil were determined by using standard methods.

Results of mycoflora analysis, myctoxin evaluation in oilseeds and oil extracted from the healthy and infected samples were analyzed by using SPSS Package (1977). Standard errors of means (S. E. M.) and critical differences were computed to draw appropriate inferences.

\section{Results}

\subsection{Mycoflora Analysis}

The percentage incidence of mycoflora associated with TBOS understudy is presented in Table 1. A total of Seven fungi comprising Aspergillus flavus, A. niger, Alternaria alternata, Fusarium pallidoroseum, F. verticillioides, Penicillium citrinum and Rhizopus stolonifer isolated from fresh samples of oilseeds under study. Four fungi namely Aspergillus flavus, A. niger, Fusarium pallidoroseum and Penicillium citrinum were isolated from fresh seed kernels of $B$. lanzan whereas A. alternata, A. flavus, A. niger and P. citrinum were isolated from the fresh seed kernels of $J$. regia. Fresh samples of $S$. robusta exhibited presence of five fungi i.e. A. alternata, A. niger, A. flavus, Fusarium and $R$. stolonifer. No fungus was observed on fresh seed kernels of $P$. armeniaca (Table 1).

Eighteen fungi namely Aspergillus flavus, A. niger, A. ochraceus, Alternaria alternata, Capnodium sp., Chaetomium globosum, Cladosporium clsadosporioides, C. herbarum, Curvularia lunata, Cylindrocladium sp., Fusarium pallidoroseum, F. solani, F. verticillioides, Penicillium citrinum, Phoma sp., Syncephalastrum racemosum, Trichothecium roseum and Rhizopus stolonifer were isolated from the stored samples of oilseeds.

Nine fungi namely A. flavus, A. niger, Capnodium sp., C. lunata, F. pallidoroseum, F. solani, F. verticillioides, $P$. citrinum and $R$. stolonifer were recorded on stored seed kernels of $B$. lanzan with percentage incidence $35,13.5,15.4,12.5,13,8,13.2$ 1nd 12\% respectively. Highest percentage incidence was recorded of $A$. flavus (35\%) followed by C. lunata (15.4\%), A. niger (13.5\%) and P. citrinum (13.2\%). Three known mycotoxin producing fungi $A$. flavus, F. verticillioides and $P$. citrinum were recorded from the seed kernels of $B$. lanzan.

Stored kernels of Prunus armeniaca showed presence of six fungi namely Aspergillus flavus, A. niger, A. ochraceus, F. verticillioides, Penicillium citrinum and Rhizopus sp. With percentage incidence 25, 23.2, 19.2, 12, 11 and $10.6 \%$ respectively. Highest percentage incidence was recorded in case of A. flavus (25\%), followed by $A$. niger (23.2\%) and A. ochraceus (19.2\%) followed by other fungi. 
Table 1. Mycoflora analysis in oilseeds

\begin{tabular}{|c|c|c|c|c|c|c|c|c|c|}
\hline \multirow{2}{*}{$\begin{array}{l}\text { S. } \\
\text { N. }\end{array}$} & \multirow[t]{2}{*}{ Mycoflora } & \multicolumn{2}{|c|}{ B. lanzan } & \multicolumn{2}{|l|}{ J.regia } & \multicolumn{2}{|c|}{ P. armeniaca } & \multicolumn{2}{|l|}{ S. robusta } \\
\hline & & Fresh & Stored & Fresh & Stored & Fresh & Stored & Fresh & Stored \\
\hline 1 & $\begin{array}{lll}\text { Alternaria } & \text { alternata } \\
\text { Keissler } & & \end{array}$ & - & - & $16.0 \pm 2.2$ & $16.4 \pm 0.89$ & - & - & $9.6 \pm 1.8$ & $22.5 \pm 0.42$ \\
\hline 2 & Aspergillus flavus Link : Fries & $9.4 \pm 1.4$ & $35 \pm 0.75$ & $11 \pm 1.4$ & $27 \pm 1.35$ & - & $25 \pm 1.35$ & $13.8 \pm 1.09$ & $19.0 \pm 1.25$ \\
\hline 3 & A. niger Van Teigh & $12 \pm 1.4$ & $13.5 \pm 0.2$ & $10.6 \pm 1.0$ & $12.6 \pm 1.12$ & & $23.2 \pm 0.92$ & $16.4 \pm 1.12$ & $19.6 \pm 0.97$ \\
\hline 4 & A.ochraceus Wilhem & - & - & - & $18 \pm 1.03$ & - & $19.2 \pm 0.96$ & - & - \\
\hline 5 & Capnodium sp. & - & $15.4 \pm 0.11$ & - & - & - & - & - & - \\
\hline 6 & Chaetomium globosum Kunze & - & - & - & $11.2 \pm 1.35$ & - & - & - & - \\
\hline 7 & $\begin{array}{l}\text { Cladosporium cladosporioides } \\
\text { (Fres.) de Vries }\end{array}$ & - & - & - & - & - & - & - & $31.0 \pm 1.72$ \\
\hline 8 & C. herbarum (Pers.) Link) & - & - & - & $19.6 \pm 0.96$ & - & - & - & - \\
\hline 9 & Curvularia lunata (Wak.) Boed & - & $15.4 \pm 1.1$ & - & - & - & - & - & - \\
\hline 10 & Cylindrocladium sp. & - & - & - & - & - & - & - & $14.8 \pm 1.01$ \\
\hline 11 & Fusarium pallidoroseum (Cooke) & $6 \pm 0.23$ & $12.5 \pm 2.2$ & - & - & - & - & - & - \\
\hline 12 & F. solani (Mart.) Sacc. & - & $13.0 \pm 1.6$ & - & - & - & - & - & - \\
\hline 13 & F. verticillioides Sacc. & - & $8 \pm 0.95$ & - & $18.4 \pm 0.58$ & - & $12 \pm 1.24$ & $14.5 \pm 0.64$ & $19.6 \pm 1.38$ \\
\hline 14 & Penicillium citrinum (Thom) & $8.7 \pm 1.8$ & $13.2 \pm 1.2$ & & & & $11.0 \pm 1.86$ & - & $12.8 \pm 0.97$ \\
\hline 15 & Phoma sp. & - & - & - & - & - & - & - & $23.6 \pm 1.58$ \\
\hline 16 & R. stolonifer Ehren: Fries & - & $12 \pm 2.1$ & - & $16.4 \pm 74$ & - & $-10.6 \pm 1.56$ & $19.2 \pm 1.35$ & $23.3 \pm 0.25$ \\
\hline 17 & $\begin{array}{l}\text { Syncephalastrum Racemosum } \\
\text { Schroet }\end{array}$ & - & - & - & $13.8 \pm 1.09$ & - & - & - & - \\
\hline 18 & Trichothecium roseum Link:Gray & - & - & - & $9.4 \pm 1.4$ & - & - & - & - \\
\hline
\end{tabular}

A total of nine fungi namely Alternaria alternata, Aspergillus niger, A. flavus, Chaetomium globosum, Cladosporium herbarum, Penicillium citrinum, Rhizopus sp., Syncephalastrum racemosum and Trichothecium roseum were isolated from stored $J$. regia kernels and their percentage incidence was 27, 12.6, 18, 16.4, 11.2, 18.4, 13.8, 9.4 and $16.4 \%$ respectively. Highest incidence recorded was of A. flavus (27\%), followed by $C$. herbarum (19.6\%), P. citrinum (18.4\%) and A. ochraceus (18\%).

Stored kernels of Shorea robusta exhibited presence of nine fungi namely Alternaria alternata, Aspergillus flavus, A. niger, Cladosporium cladosporioides, Cylindrocladium sp., Phoma sp., Fusarium moniliforme, P. citrinum and $R$. stolonifer with percentage incidence of 19, 19.6, 22.5, 31, 14.8, 19.6, 12.8, 23.6 and 23.3\% respectively. Highest incidence recorded was of $C$. cladosporioides (31\%) followed by Phoma sp. (23.6\%), $R$. stolonifer $(23.3 \%)$, A. alternata $(22.5 \%)$ followed by other fungi. In this case also, the mycotoxin producing fungi $A$. flavus, $F$. verticillioides and $P$. citrinum were recorded with $19,19.6$ and $12.8 \%$ incidence respectively.

A. flavus, A. niger and P. citrinum were recorded as the most frequently occurring fungi in seed kernels of $B$. lanzan, J. regia, P. armeniaca and S. robusta.

\subsection{Toxigenic Potential of Mycotoxin Producing Fungi}

Aflatoxins were the most common mycotoxins elaborated by different isolates of Aspergillus flavus isolates from B. lanzan. Out of 35 isolates of A. flavus 9 were toxigenic and produced aflatoxins in the liquid medium. Aflatoxin $B_{1}$ was elaborated by 5 isolates whereas 3 isolates produced $A f l . B_{1}$ and $B_{2}$, whereas only one produced Afl. $\mathrm{B}_{1}, \mathrm{~B}_{2}$ and $\mathrm{G}_{1}$. In case of $J$. regia, 9 isolates out of 37 screened produced aflatoxins. Aflatoxin B1 was produced by 5 and aflatoxin $\mathrm{B}_{1} \mathrm{~B}_{2}$ by 4 isolated. In case of Prunus armeniaca 2 isolates of $A$. flavus produced aflatoxin $B_{1}$ and 1 produced aflatoxin $B_{1} B_{2}$ out of 25 isolated screened for aflatoxin producing ability. 
On the other hand in $S$. robusta, 4 isolates were aflatoxin positive, 2 produced aflatoxin $\mathrm{B}_{1}$ and 2 produced aflatoxin $\mathrm{B}_{1} \mathrm{~B}_{2}$ out of 199 screened for presence of aflatoxins. The amount of aflatoxin produced by the toxigenic isolates of $A$. flavus was in the range of ( up to $26 \mu \mathrm{g} / \mathrm{ml}$ in B. lanzan, $19 \mu \mathrm{g} / \mathrm{ml}$ in J. regia, $4 \mu \mathrm{g} / \mathrm{ml} P$. armeniaca, $3.5 \mu \mathrm{g} / \mathrm{ml}$ in S. robusta (Table 2).

Table 2. Screening of fungi for mycotoxin producing potentials

\begin{tabular}{|c|c|c|c|c|c|}
\hline Oilseed samples & Fungi & $\begin{array}{l}\text { No. of } \\
\text { isolates } \\
\text { screened }\end{array}$ & $\begin{array}{l}\text { No. of toxigenic } \\
\text { isolates }\end{array}$ & $\begin{array}{l}\text { Mycotoxin } \\
\text { produced }\end{array}$ & $\begin{array}{l}\text { Level of } \\
\text { mycotoxin } \\
(\mu \mathrm{g} / \mathrm{ml})\end{array}$ \\
\hline \multirow[t]{6}{*}{ B. lanzan } & A. flavus & 35 & 9 & Aflatoxins & $0.9-26.0$ \\
\hline & & & 5 & Aflatoxin B1 & \\
\hline & & & 3 & AflatoxinB1B2 & \\
\hline & & & 1 & Afl.B1B2G1 & \\
\hline & F. verticillioides & 19 & 2 & Zearalenone & traces \\
\hline & P. citrinum & 23 & 7 & Citrinin & $0.2-3.5$ \\
\hline \multirow[t]{5}{*}{ J. regia } & A. flavus & 37 & 9 & Aflatoxins & $0.4-19$ \\
\hline & & & 5 & Aflatoxin B1 & \\
\hline & & & 4 & AflatoxinB1B2 & \\
\hline & A. ochraceus & 19 & 7 & Ochratoxin & $0.2-3.5$ \\
\hline & P. citrinum & 33 & 9 & Citrinin & $0.48-6.0$ \\
\hline \multirow[t]{6}{*}{ P. armeniaca } & A. flavus & 25 & 3 & Aflatoxins & $0.2-4.0$ \\
\hline & & & 2 & Aflatoxin B1 & \\
\hline & & & 1 & Afl.B1B2 & \\
\hline & A. ochraceus & 12 & 3 & Ochratoxin & Traces \\
\hline & F. verticillioides & 21 & 4 & Zearalenone & Traces- -0.62 \\
\hline & P. citrinum & 11 & 2 & Citrinin & traces \\
\hline \multirow[t]{5}{*}{ S. robusta } & A. flavus & 19 & 4 & Aflatoxins & $0.6-3.5$ \\
\hline & & & 2 & Aflatoxin B1 & \\
\hline & & & 2 & Afl. B1B2 & \\
\hline & F. verticillioides & 23 & 5 & Zearalenone & $0.12-4.0$ \\
\hline & P. citrinum & 17 & 2 & Citrinin & Traces \\
\hline
\end{tabular}

The percentage toxigenicity was comparatively lower in the isolates of other mycotoxigenic fungi from all samples. Seven isolates of A. ochraceus from J. regia (out of nineteen screened) and three from P. armeniaca (out of 12 screened) elaborated ochratoxin in the range of $0.2-3.5 \mu \mathrm{g} / \mathrm{ml}$. Out of 19, 21 and 23 isolates of $F$. verticillioides obtained from $B$. lanzan, P. armeniaca and $S$. robusta samples respectively, only 2,4 and 5 were toxigenic and produced zearalenone up to $4 \mu \mathrm{g} / \mathrm{ml}$. Citrinin was elaborated by 7 isolates of P. citrinum obtained from B. lanzan (23 screened), 9 from J. regia (33 screened), 2 from P. armeniaca (11 screened) and 2 from $S$. robusta (17 screened) and the range varied from $0.2-6 \mu \mathrm{g} / \mathrm{ml}$.

\subsection{Mycotoxin Contamination in Oil Seed Samples}

Fifty-five samples of $B$. lanzan were analyzed for the natural contamination of mycotoxins, out of which 23 were found to be contaminated with aflatoxins and zearalenone. Out of 58 samples of $J$. regia, 27 were contaminated with aflatoxins and citrinin. In case of P. armeniaca, 52 samples were analyzed out of which 19 produced aflatoxins and ochratoxins while only seven out of 22 samples of $S$. robusta analyzed produced aflatoxins and zearalenone (5 with aflatoxins and 2 with zearalenone) (Table 3 ). 
Table 3. Natural contamination of mycotoxins in oilseed samples

\begin{tabular}{lccccc}
\hline Substrate & \multicolumn{2}{c}{ No. of samples } & $\begin{array}{c}\text { No. of } \\
\text { positive } \\
\text { samples }\end{array}$ & $\begin{array}{c}\text { Mycotoxin } \\
\text { detected }\end{array}$ & $\begin{array}{c}\text { Level of } \\
\text { mycotoxin } \\
(\boldsymbol{\mu g} / \mathbf{g})\end{array}$ \\
\cline { 2 - 5 } B. lanzan & 55 & Contaminated & 19 & Aflatoxins & $0.08-0.48$ \\
& & 23 & 4 & Zeara. & - \\
J. regia & 58 & 27 & 21 & Aflatoxins & $0.14-0.54$ \\
& & & & Citrinin & $0.06-0.17$ \\
P. armeniaca & 52 & 19 & 14 & Aflatoxins & $0.18-0.98$ \\
& & & 5 & Och A & $0.03-0.06$ \\
S. robusta & 22 & 7 & 5 & Aflatoxins & 0.2400 .91 \\
& & & 2 & Zeara. & $0.09-0.12$ \\
\hline
\end{tabular}

In B. lanzan, J. regia, P. armeniaca and S. robusta, the level of naturally contaminated aflatoxins was up to 0.48 , $0.54,0.93$ and $0.91 \mu \mathrm{g} / \mathrm{g}$ respectively. Zearalenone was detected in four samples of $B$. lanzan and two samples of $S$. robusta and the concentration was up to 0.04 and $0.12 \mu \mathrm{g} / \mathrm{g}$ respectively. Ochratoxins were detected in only five samples of $P$. armenica and the concentration was up to $0.06 \mu \mathrm{g} / \mathrm{g}$ while citrinin $(0.14 \mu \mathrm{g} / \mathrm{g})$ was detected in six samples of $J$. regia only.

A significant change was observed in the oil content of healthy and fungal infected oilseed samples. In healthy seed kernels of B. lanzan, J. regia, P. armeniaca and S. robusta oil content was 42.15, 57.08, 48.95 and $17.95 \%$ respectively. Fungal infestation reduced the yield of oil and the yield was 41.03, 56.28, 48.43 and $16.43 \%$ in $P$. citrunum infested samples; 39.06, 55.24, 47.30 and 15.51\% in A. flavus infested samples and 41.27, 56.55, 47.38 and $17.43 \%$ in $A$. niger infested samples of B. lanzan, J. regia, P. armeniaca and S. robusta respectively (Table 4).

Table 4. Changes in oil content due to fungal infestation

\begin{tabular}{lllll}
\hline Treatment & \multicolumn{2}{l}{ Oil content (\%) } & & \\
\cline { 2 - 5 } & S. robusta & B. lanzan & P. armeniaca & J. regia \\
\hline Control & $17.35 \pm 0.27$ & $42.15 \pm 0.61$ & $48.96 \pm 0.26$ & $57.08 \pm 0.42$ \\
P. citrinum & $16.43 \pm 0.13$ & $41.03 \pm 0.40$ & $48.44 \pm 0.14$ & $56.28 \pm 0.15$ \\
A. flavus & $15.51 \pm 0.23$ & $39.06 \pm 0.61$ & $47.30 \pm 0.09$ & $55.25 \pm 0.09$ \\
A. niger & $17.43 \pm 0.36$ & $41.27 \pm 0.13$ & $47.39 \pm 0.45$ & $56.56 \pm 0.13$ \\
$\mathrm{SEM} \pm$ & 0.47 & 0.56 & 0.35 & 0.33 \\
$\mathrm{CD}(0.05)$ & 2.11 & 2.53 & 1.57 & 1.49 \\
\hline
\end{tabular}

\subsection{Natural Occurrence of Aflatoxins in Oil Samples}

Analysis of oil, extracted from the seed samples, has been carried out for aflatoxin level. It showed the presence of aflatoxin $B_{1}$ in $28 \%$ sample of sal butter up to $0.23 \mu \mathrm{g} / \mathrm{g}$. Twenty percent $(20 \%)$ sample of apricot oil were positive and the level of aflatoxin $B_{1}$ ranged from traces to $0.32 \mu \mathrm{g} / \mathrm{g}$. In case of chironji oil and walnut oil, $18 \%$ and $20 \%$ samples respectively were positive and produced aflatoxin $\mathrm{B}_{1}$ up to $0.28 \mu \mathrm{g} / \mathrm{g}$ (Table 5).

Table 5. Natural contamination of aflatoxins in oil samples

\begin{tabular}{llll}
\hline Oil samples & \multicolumn{1}{c}{ No. of samples } & $\begin{array}{l}\text { Level of Aflatoxins } \\
(\boldsymbol{\mu g} / \mathbf{g})\end{array}$ \\
\cline { 2 - 3 } & Screened & Contaminated & 0.28 \\
B. lanzan & 25 & 4 & 0.28 \\
J. regia & 30 & 6 & 0.32 \\
P. armeniaca & 30 & 6 &
\end{tabular}




$\begin{array}{llll}\text { S. robusta } & 25 & 7 & 0.23\end{array}$

Fatty acid composition of the methyl esters of oil obtained from seed kernels of B. lanzan, J. regia, P. armeniaca and $S$. robusta was determined. Due to fungal infestation, change in the concentration of fatty acids was observed.

\section{Discussion}

A varied pattern of mycoflora was observed on seed kernels of B. lanzan, J. regia, P. armeniaca and S. robusta. Relatively low fungal count was recorded on fresh seed kernels. It was observed that a large number of fungi including A. flavus, A. ochraceus, F. verticillioides and P. citrinum were associated with stored kernels of $B$. lanzan, J. regia, P. armeniaca and S. robusta. Association of fungus as well as their incidence is governed by the nature of the substrates, method of storage as well as the prevailing climatic conditions. Earlier reports also indicate association of large number of mycoflora and mycotoxins in edible and medicinal fruits/seeds of forest origin (Zohari et al., 1987; Reichert, 1988; Abdel Hafez \& Saber, 1993; Singh et al., 2001; Singh, 2003).

Infection and entry of $A$. flavus in the substrate may occur as a result of biological and mechanical injury development of fruits/seeds and transportation from forest to store house. It has been established that growth of A. flavus and subsequent aflatoxin production depend upon the colonization and biological properties of coinvading fungal partners (Wicklow et al., 1980; Roy \& Chourasia, 1990). The behavior of A. flavus isolates to produce different types of aflatoxins may be due to genetic make up of the host (Zuber et al., 1978), moisture stress and co-invading fungal partners (Wicklow et al., 1987).

Stored kernels of all the four types of oil seeds B. lanzan, J. regia, P. armeniaca and S. robusta were naturally contaminated with mycotoxin, although their incidence varied with the nature of the substrate. This might be due to difference in their moisture contents and constitutional make up. It is believed that the fungi evolve these metabolites i.e. mycotoxins as a means of protecting their food supply.

The natural contamination of mycotoxins in the stored samples corresponded to the incidence of toxigenic fungi associated with them and their respective potentiality to produce mycotoxins in the synthetic media. $B$. lanzan kernels were found as the most suitable substrate to produce mycotoxins where aflatoxins were present in its higher concentration; the concentration of aflatoxin in other kernels was also quite high. High concentration of aflatoxins in edible and medicinal fruits/seeds of forest origin has been reported by Zohari et al. (1987), Reichert (1988), Abdel Hafez and Saber (1993), Khan and Singh (2000) and Singh et al. (2001).

There are reports on association of mycotoxin producing fungi and incidence of mycotoxins on forest produce such as apricot, fig, nutmeg, walnut, crude drugs, chilgoza, neem etc. (Singh \& Shukla, 2008; Reichert et al., 1988; Takahashi, 1993; Lohani et al., 1995; Gurses \& Erdogan, 2004). Oilseeds, groundnut oil, and their butter and cake are reported to be contaminated with mycotoxins (Mehan and Mc Donald, 1982; Ram et al., 1986; Abalaka \& Elegbede, 1982). Besides this olive oil, corn oil, coconut oil has been found contaminated with different level of mycotoxins (Papachriston and Markaki, 2004, Blesha et al., 2004). Kershaw (1982) working on mycotoxin contamination in sal butter reported higher concentration of aflatoxin $\mathrm{B}_{1}$.

Aspergillus flavus group of fungi cause deterioration in the nutritive quality of the food materials by producing aflatoxins and by changing some of the chemical constituents of the substrates. Marked depletion in oil content was recorded due to fungal infestation. Analysis of methyl esters of oil obtained from healthy and infested seed kernels reflected changes in the relative concentration of fatty acids during fungal infection. Depletion in fatty acid content under infestation may be attributed to their utilization or degradation into simpler forms (Singh \& Shukla, 2005).

The concentration of aflatoxin $\mathrm{B}_{1}$ in oilseed samples as well as in the toxigenic A. flavus isolates was above the tolerance level (30ppb) fixed by World Health Organization. Ingestion of mould contaminated food/ foodstuffs may cause animal mycotoxicoses. Naturally occurring mixtures of aflatoxins particularly aflatoxin $\mathrm{B}_{1}$ has been classified as class I human carcinogens (IARC, 1993). The aflatoxin has been of immense interest to scientists because of their deleterious effects on animal health and acute toxicological effects in man (Wood, 1992). Aflatoxin contaminated food is a serious cause of illness and death in developing countries which have fewer safety regulations. The effect of fungal infestation on carbohydrate, protein and fats and oils is of special significance on account of their food value.

There is a need to restrict the use of mycotoxin-contaminated samples for direct consumption or for extraction of edible oils by the industries. The TBOS used for edible and medicinal purposes must be graded and screened against Aspergillus flavus, a potent mycotoxin producing fungi. Appropriate storage practices should be implemented to avoid fungal infection and decrease the probability of mycotoxin contamination in edible oil. For 
better quality oil, it is recommended to extract oil from fresh and screened seed samples, instead of storing the seeds, oil should be stored for longer duration.

\section{Conclusion}

In the present study, the concentration of aflatoxin $\mathrm{B}_{1}$ in oilseed samples as well as in the toxigenic $A$. flavus isolates was above the tolerance level (30ppb) fixed by World Health Organization. Ingestion of mould contaminated food/ foodstuffs may cause animal mycotoxicoses. Naturally occurring mixtures of aflatoxins particularly aflatoxin $B_{1}$ has been classified as class I human carcinogens (IARC, 1993). The aflatoxin have been of immense interest to scientists because of their deleterious effects on animal health and acute toxicological effects in man (Wood, 1992). Aflatoxin contaminated food is a serious cause of illness and death in developing countries which have fewer safety regulations. The effect of fungal infection on carbohydrate, protein and fats and oils is of special significance on account of their food value.

There is a need to restrict the use of mycotoxin-contaminated samples for direct consumption or for extraction of edible oils by the industries. The TBOS used for edible and medicinal purposes must be graded and screened against Aspergillus flavus, a potent mycotoxin producing fungi. Appropriate storage practices should be implemented to avoid fungal infection and decrease the probability of mycotoxin contamination in edible oil. For better quality oil, it is recommended to extract oil from fresh and screened seed samples, instead of storing the seeds, oil may be stored for longer duration.

\section{Acknowledgements}

The author is thankful to Science \& Engineering Research Council, Department of Science \& Technology (SERC - DST), Govt. of India for providing financial support under Women Scientist Scheme to carry out the present study. Thanks are also due to the Director, Forest Research Institute, DehraDun for necessary lab. facilities.

\section{References}

Abalaka, J. A., \& Elegbedge, J. A. (1982). Aflatoxin distribution and total mirobial counts in edible oil extracting plant. Food Chem. Toxicol., 20(1), 43-46.

Abdel-Hafez, A. I. I., \& Saber Sabah, M. (1993). Mycoflora and mycotoxin in hazelnut (Corylus avellana) and walnut (Juglans regia) seeds in Egypt. Zentralb Mikrobiol, 148 (2), 137-147.

Ainsworth, G. C., \& Austwick, P. K. C. (1973). Fungal diseases of animals, $2^{\text {nd }}$ ed. (Commomwealth agricultural Bureau) Slough, U. K.

AOAC. (1984). In Official Methods of Analysts. Association of official analytical Chemists. Verginia, USA: pp. 477-500.

Blesha, J, Soriano, J. M., Molto, J. C., \& Manes, J. (2004). Limited survey for the presence of aflatoxins in food from local market and supermarket in Valencia, Spain. Food Addit. Contaminant, 21, 165-171.

Davis, N. D., Sansing, G. A., Ellenburg, T. V., \& Diener, U. L. (1972). Appl. Microbiology, 23(2), 433-435.

Davis, N. D., Searcy, J. W., \& Diener, U. L. (1969). Production of ochratoxin A by Aspergillus ochraceus in a semisynthetic medium. Applied Microbiology, 17, 742-744.

Diener, U. L., \& Davis, N. D. (1966). Aflatoxin production by isolates of Aspergillus flavus. Phytopathology, 56(12), 1390-1393.

Gourama, H., \& Bullerman, L. B. (1995). Inhibition of growth and aflatoxin production of A. flavus by Lactobacillus sp. J. Food Prot, 58, 1249-1256.

Gurses, M., \& Erdogan, A. (2004). The study for aflatoxin B1 contamination of groundnut, pistachio and almonds sold in Erzunum. Ziraat- Facultesi-Dergisi-Ataturk-universitesi, 35(1/2), 75-78.

Hesseltine, C.W. (1965). A millennium of fungi, food and fermentation. Mycologia 57, 149-197.

IARC. (1993). IARC Monograph 56. Some naturally occurring substance: Food Items and Constituents, Heterocyclic Aromatic, Amines and Mycotoxins. International Agency for Research on Cancer, Lyon, France.

International Seed Testing Association. (1999). Seed Sci Technol, 27 (Suppl).

Jelinek, C. F., Pohl, A. E., \& Wood, G. E. (1989). Worldwide occurrence of mycotoxins in foods and feeds - an update. J. Assoc.Off. Anal. CHem., 72, 223-230.

Kershaw, S. J. (1982). Occurrence of aflatoxins in oilseeds providing cacoa butter substitute. Applied and 
Environmental Microbiology, pp. 1210-1212.

Khan, S. N., \& Singh, P. K. (2000). Mycotoxin producing potential of seed mycoflora of some forest trees. Indian Forester, 126, 1231-1233.

Lohani, S., Hoque, M. M., Begum, F., Joarder, G. K. (1995). Production of toxins by A. flavus isolates from oilseeds of Bangladesh. $J$. of Scientific and Industrial Research, 30(4), 113-118.

Mehan, V. K., \& Mc Donald, D. (1982). Mycotoxin producing fungi in groundnut potential for mycotoxin contamination. In Proc. International Symp. On mycotoxins and phytotoxins, Vienna, Austria, Pp. 98-101.

Nabney, J., \& Nesbitt, B. F. (1965). A spectrophotometric method for determining the aflatoxins. Analyst, 90, 155- 160.

Papachriston, A., \& Markaki, P. (2004). Determination of ochratoxin an in virgin oils og Greek origin by immunoaffinity column clean-up and high performance liquid chromatography. Food additives and contaminants, 21(1), 85-92.

Punam, K. Singh, \& Shukla, A. N. (2008). Survey of mycoflora counts, aflatoxin contamination and induced biochemical changes in walnut kernels. J. Stored Product Research, 44, 169-172.

Ram, B. P., Hart, P., Cole, R. J., \& Pestka, J. J. (1986). Application of ELISA to retail survey of aflatoxin B1 in Peanut butter. J. Food Protect, 49, 792-796.

Reichert, N. (1988). Determination of afl. $B_{1}$ in dries figs by visual screening and thin layer chromatography. $Z$ Lebensm- Uter-Forsch, 186, 505-508.

Rensburg, S. J. Van, Cook-Mozaffari, P., Schalkwyk, V. (1985). Hepatocellular carcinoma and dietary aflatoxin in Mozambique and Transkei. Br. J. Cancer, 51, 713-726.

Roberts, B. A., \& Patterson, D. S. P. (1975). Detection of twelve mycotoxins in mixed animal feedstuffs, using a novel membrane clean-up procedure. J. Assoc. Off. Anal. Chem., 58, 1178-1181.

Roy, A. K., \& Chourasia, H. K. (1990). Inhibition of aflatoxin production by microbial interaction. J. Gen. App Microbiol, 38, 59-62.

Schwenk, E., Alexander, G. J., Gold, A. M., \& Stevens, D. F. (1958). Biogenesis of citrinin. J. Biol. Chem., 233(5), 1211-1213.

Scott, P. M., Lawrence, J. W., \& Vam Walbeek, W. (1970). Detection of mycotoxins by Thin Layer Chromatography: application to screening of fungal extracts. Appl. Microbiol, 19, 839-842.

Shukla, A. N., \& Punam K. Singh. (2006). Fungal infestation and aflatoxin contamination in edible oilseeds of forest origin. J. Mycol \& Plant Pathology, 36(1), 96-100.

Shukla, R., Kumar, A., Singh, P., \& Dubey, N. K. (2009). Efficacy of Lippia alba (Mill.) N.E. Brown essential oil and its monoterpene aldehyde constituents against fungi isolated from some edible legume seeds and aflatoxin $\mathrm{B}_{1}$ production. International journal of Food Microbiology, 135, 165-170.

Singh, P. K, Khan, S. N., Harsh, N. S., \& Pandey, R. (2001). Incidence of mycoflora and mycotoxins in some edible fruits and seeds of forest origin. Mycotoxin Research, 17(2), 46-58.

Singh, P. K. (2003). Mycotoxin elaboration in Triphala and its constituents. Ind. Phytopath, 56(4), 380-383.

Singh, P. K., \& Shukla, A. N. (2008). Survey of mycoflora counts, aflatoxin production and induced biochemical changes in walnut kernels. J. Stored Product Research, 44, 169-172.

SPSS-Statistical Package for Social Sciences. SPSS Inc. (1977). SPSS Base Statistics, version 7.5, Chicago.

Stack, M. E., \& Pohland, A. E. (1975). Collaborative study of a method for chemical confirmation of the identify of aflatoxin. J Assoc off Anal Chem, 33, 110-113.

Thomas, F., Eppley R. M., \& Truckess, M. W. (1975). Rapid screening method for aflatoxins and zearalenone in corn. J. assoc. Off. Anal Chem, 58, $114-116$.

Wicklow, D. T., Hesseltine, C. W., Shotwell, O. L., \& Adams, G. L. (1980). Interface competition and aflatoxin levels in corn. Phytopathology, 70, 761-764.

Wilson, D. M., \& Payne, G. A. (1994). Factors affecting Aspergillus flavus group infection and aflatoxin contamination of crops. In The Toxicology of aflatoxins,Human Health, Veterinary, and Agricultural Significance (David L. Eaton and John D.Groopman, San Diego:Academic Press, 1994).

Wood, G. E. (1992). Mycotoxins in food and feed in U. S. A. J. of Animal Science, 70, 3941-3949.

Zohari, A. A., \& Abdel- Gaward Kharia, M. (1987). Survey of mycoflora and mycotoxins of some dried fruits in 
Egypt. J. Basic Microbiol, 33, 279-285. 